\title{
Integralidade à saúde da mulher e psicologia: Análise da produção científica brasileira
}

\author{
Integrality of women's health and psychology: An analysis on Brazilian scientific production
}

Adolfo Pizzinato $^{[a]}$, Greice da Silva Carvalho[b], João Pedro Cé[e], Rodrigo de Oliveira Machado ${ }^{[d]}$, Marlene Neves Strey ${ }^{[e]}$

\footnotetext{
[a] Doutor em Psicologia e professor do Programa de Pós-Graduação em Psicologia da Pontifícia Universidade Católica do Rio Grande do Sul (PUCRS), Porto Alegre, RS - Brasil, e-mail: adolfo.pizzinato@pucrs.br

${ }^{[b]}$ Graduada em Psicologia pela Pontifícia Universidade Católica do Rio Grande do Sul (PUCRS), Porto Alegre, RS - Brasil, e-mail: greicecarvalho@gmail.com

${ }^{[c]}$ Graduando em Psicologia pela Pontifícia Universidade Católica do Rio Grande do Sul (PUCRS), Porto Alegre, RS - Brasil, e-mail: joão.ce@acad.pucrs.br

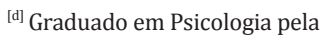
Pontifícia Universidade Católica do Rio Grande do Sul (PUCRS), Porto Alegre, RS - Brasil, e-mail: rodrigo.machado@acad.pucrs.br

${ }^{[\mathrm{e}]}$ Doutora em Psicologia, professora do Programa de Pós-Graduação em Psicologia da Pontifícia Universidade Católica do Rio Grande do Sul (PUCRS), Porto Alegre, RS - Brasil, e-mail: strey@pucrs.br
}

Recebido: 14/12/2010 Received: 12/14/2010

\section{Resumo}

Este texto analisa a produção científica sobre a Integralidade no Brasil, enfatizando especialmente o papel da Psicologia na construção dessa perspectiva de entendimento dos processos de cuidado na saúde/doença no Brasil. Para isso realizou-se uma busca bibliográfica nas bases de dados eletrônicas PEPSIC e Scielo, entre os meses de março e abril de 2010. Utilizou-se o descritor "integralidade" como motor de busca e, dentro dos artigos encontrados, analisaram-se com especial atenção as associações entre integralidade e saúde da mulher. Para esclarecer a panorâmica da produção na área, foram analisadas cinco categorias nos textos: tipo de artigo, tipo e nome das revistas, formação dos autores e autoras, ano de publicação e população da pesquisa. Os resultados encontrados apontam que os psicólogos/as estão produzindo menos que os/as demais profissionais da área da saúde e que a Integralidade proposta, enquanto marco norteador da atenção à saúde da mulher, ainda é insipiente na práxis psicológica.

Palavras-chave: Integralidade. Saúde da mulher. Psicologia.

\begin{abstract}
The present text performed an analysis on the scientific production about Integrality in Brazil, especially on the role of psychology in constructing this scope of understanding the health/disease process on the referred country. Bibliographic research was made on the electronic databases of PEPSIC and Scielo, between March and April 2010. The key word used in search engines was "Integralidade" (integrality) and within the articles found the associations about women's health and the relation with "integralidade" were especially analyzed. Five categories were elected to elucidate the production in the area: type of article, type and name of journal, authors' background and year of publication and number of people sampled in the study. Results found point that psychologists are producing less than other health professionals and integrality, as main driver for women's healthcare work is not yet consolidated.
\end{abstract}

Keywords: Integrality. Women's health. Psychology. 


\section{Introdução}

Este texto analisa a produção científica sobre integralidade na atenção à saúde, enfatizando o papel do discurso $p$ si nesse processo de construção de conhecimento, em especial no que diz respeito à Saúde da Mulher. Para efetuar a discussão, foi feito um levantamento, no qual se encontraram dados referentes à produção acadêmica sobre integralidade e sobre o posicionamento da Psicologia nessa produção.

Foi delineado um levantamento que pudesse responder, ou pelo menos tentar buscar as razões da ausência explícita de interlocução entre as práticas psicológicas na área da saúde coletiva e a produção de um referencial próprio na área e, em especial no que diz respeito à integralidade - tanto enquanto Política de Atenção à Saúde, como enquanto perspectiva epistemológica. 0 marco escolhido dentro da Psicologia foi o da Psicologia Social da Saúde (Spink, 2003).

Existem divergências de perspectiva no que se refere à apropriação - por parte da Psicologia - do conceito de saúde. Segundo Spink (2003), a Psicologia se apresenta relacionada ao conceito de saúde, mas não classicamente enquanto constituinte do mesmo. Existe grande identificação com algumas denominações de saúde, como, por exemplo, a da Organização Mundial da Saúde, que a concebe como o bem-estar físico, mental e social. Porém, a Psicologia, enquanto disciplina, se aproxima tardiamente à área da saúde.

... temos atualmente, uma Sociologia da saúde, uma Antropologia da saúde e, até mesmo, uma Economia da saúde ... . A psicologia chega tarde neste cenário e chega 'miúda', tateando, buscando ainda definir seu campo de atuação, sua contribuição teórica efetiva e as formas de incorporação do biológico e do social ao fato psicológico, procurando abandonar os enfoques centrados em um indivíduo abstrato e a-histórico tão frequentes na psicologia clínica tradicional (Spink, 2003, p. 30).

A Psicologia funda-se como ciência, em meados do século XIX, tendo como foco os processos da consciência e sem intenção de investir em questões relativas à saúde, já que tinha como condição, indivíduos "normais". Ao mesmo tempo que esse processo começa a ser instaurado nas sociedades Ocidentais há um modo de organização social, em que começam as práticas de higiene social, a Medicina investe na compreensão e normatização dos processos de saúde e doença dos grupos sociais. Quando a Psicologia volta-se para os fenômenos de normalidade e anormalidade, funda uma interioridade na qual se encontram as condições para a produção de saúde ou doença (local onde as imperfeições e dificuldades se apresentam) de maneira diretamente influenciada pelo discurso médico, mas no sentido de responder às lacunas deixadas por aquela ordem discursiva (Medeiros, Guareschi \& Bernardes, 2005).

Conforme essas autoras, na década de 1960 houve mobilizações populares com questões sociais relacionadas aos direitos humanos, pobreza, racismo entre outros. É neste período que a Psicologia, enquanto profissão, começa a figurar nas comunidades de prática em saúde (e não em doença - psicopatologia, campo de estudo e produção de saber já configurado desde o início do século XX), dando início à Psicologia Comunitária e Hospitalar. Mesmo com ênfases radicalmente diferentes quanto a processo de trabalho, é a partir desses movimentos que há uma maior compreensão dos fenômenos psicológicos do sujeito e a potencialização de práticas de saúde. São implantados centros comunitários de saúde para efetuarem ações preventivas e cuidados básicos à população. A partir da década de 1980, a Organização Mundial de Saúde atualiza o conceito de saúde, visando à promoção de saúde, incorporando questões do desenvolvimento econômico e social. No Brasil, implanta-se o Sistema Único de Saúde (SUS), o que acaba por criar várias discussões, significando a Saúde como direito do cidadão e dever do Estado, a saúde como uma questão "integral". "A Psicologia passa, então, a figurar nas conferências de saúde e nos estabelecimentos da rede pública de saúde, reorganizando as práticas psicológicas" (Medeiros, Bernardes \& Guareschi, 2005, p. 269).

No ano de 1988, foi aprovada a nova Constituição Federal, criando, oficialmente, o SUS, que foi regulamentado pelas Leis n. 8.080, de 19 de setembro de 1990, e n. 8.142, de 28 de dezembro de 1990 (Brasil, 1990a, b). A partir daí, a saúde passa a ser entendida como resultante de políticas sociais e econômicas, como direito do cidadão e dever do Estado e como parte da seguridade social. As ações e os serviços devem ser providos por um sistema único de saúde, organizado segundo os princípios da descentralização, mando único em cada esfera de governo, com controle social e atendimento integral (Medeiros \& Guareschi, 2009). 
Tais princípios se derivam do Movimento Sanitarista Brasileiro que, desde meados do século XX, buscou ampliar o campo de atuação em saúde, em um processo de crítica à medicalização da sociedade, aos limites do saber médico e à sua racionalidade, transitando ora na tentativa de subordinação a uma racionalidade sanitária, ora na defesa do reconhecimento e incorporação de racionalidades médicas alternativas, supostamente mais próximas da integralidade (Garcia et al., 2006). A integralidade passa a ocupar no Brasil uma posição estruturante no SUS, e acompanhada outros três princípios (a universalidade, que concebe a saúde como um direito de todos; da equidade, que preconiza que todos têm igual oportunidade de utilizar os serviços de saúde; e do controle social) seria um atributo necessário de todas as práticas de todos os profissionais de saúde, pressupondo: a incorporação ou redefinição da equipe de saúde e de seus processos de trabalho; a articulação entre assistência e práticas de saúde pública; e a organização dos serviços para realizar um olhar ampliado das necessidades da população, levando em conta fatores sócio-históricos e biológicos aliando olhares humanizados ao cuidado que alavancaram a reforma sanitária, movimento de institucionalização do SUS (Brasil, 2000; Garcia et al., 2006; IDEC, 2006).

A integralidade em saúde, segundo Mattos (2001), deve ser compreendida como uma perspectiva epistemológica de matriz dialógica, processual e coletiva, agregando três conjuntos de atuação: os atributos dos profissionais de saúde, (que implicam em uma boa prática); os atributos da organização dos serviços e as respostas governamentais aos problemas de saúde.

No texto legal (Brasil, 1990a), tal conceito é entendido como o conjunto articulado e contínuo de ações e serviços preventivos e curativos, individuais e coletivos, exigidos para cada caso, em todos os níveis de complexidade do sistema. Mesclam-se, aí, ações de promoção, proteção e recuperação de agravos à saúde que, diante da complexidade que se faz presente, exige a ação de pessoas com diferentes especialidades e capacitações. A integralidade, portanto, é da ordem da multidisciplinaridade e envolve múltiplas especialidades que se entrecruzam para dar resposta às demandas e necessidades.

Com a responsabilização do Estado e a implantação do SUS (como eixo central na atenção à saúde) e tendo como um dos princípios a equidade, novas políticas necessitam ser implementadas e assim surge a Política Nacional de Atenção Integral à Saúde da Mulher (PNAISM), de 2003, com o objetivo de reduzir a mortalidade graças a causas passíveis de prevenção, além de fomentar a implementação de ações que contribuam para a garantia dos direitos humanos das mulheres (Brasil, 2004). No sentido da integralidade, essas ações governamentais visam a promover tanto ações de atenção à saúde em todas as fases da vida da mulher, abrangendo cuidados com sua saúde mental e ocupacional, quanto a ações direcionadas ao controle de doenças sexualmente transmissíveis (DSTs), de prevenção do câncer e de planejamento familiar, de modo a ir além das ações dos programas exclusivamente da saúde materno-infantil (Farah, 2004). Seus princípios norteadores são a integralidade e a promoção da saúde, sob o enfoque de gênero, buscando consolidar os avanços conquistados pelas Políticas de Saúde da Mulher (Brasil, 2004). A PNAISM delimita ações, normatiza modos de atenção à saúde e fundamenta a prática de profissionais em relação às particularidades da saúde da mulher.

A PNAISM inclui o programa de planejamento familiar, apontando-lhe como estratégias: ampliar e qualificar a atenção ao planejamento familiar, incluindo a assistência à infertilidade; garantir a oferta de métodos anticoncepcionais para a população em idade reprodutiva; ampliar o acesso das mulheres às informações sobre as opções de métodos anticoncepcionais; estimular a participação e a inclusão de homens e adolescentes nas ações de planejamento familiar (Brasil, 2004).

Segundo Medeiros e Guareschi (2009), as questões relacionadas ao gênero não aparecem inscritas na legislação sanitária, mas, sim, figuram muitas "tratativas" em relação ao gênero, que aparecem nas ações programáticas, ou seja, como se pensa o trabalho em saúde considerando o feminino. Essa omissão da discussão de gênero e conseguinte segmentarização das propostas de ação em saúde da mulher geram ações fragmentadas e objetivadas, biopoliticamente em partes do corpo feminino. Assim, não há uma "política de gênero" explícita em saúde, mas uma ação para o colo do útero, outra para as mamas, outra para a gestação[...] Estas continuam sendo as principais referências das práticas em saúdes para as mulheres, corroborando para uma visão de cuidado pautada prioritariamente na esfera biológica do ser humano, pré e pós-reprodução quando 
a mulher concebe, e, ao entrar na menopausa, deixando de ser capaz de biologicamente ter filhos, reduzindo o olhar ao feminino desconsiderando aspectos macrossociais e culturais que se atravessam nas necessidades do ser humano. Como se explicita na legislação proposta:

A área técnica de Saúde da Mulher é responsável pelas ações de assistência ao pré-natal, incentivo ao parto natural e redução do número de cesáreas desnecessárias, redução da mortalidade materna, enfrentamento da violência contra a mulher, planejamento familiar, assistência ao climatério, assistência às mulheres negras e população GLBTT (Ministério da Saúde, 2010a).

Apesar de o discurso anterior versar sobre pautas relacionadas à reprodução, neste trecho vemos ainda a caracterização da mulher no âmbito da fragilidade, pois as ações devem voltar-se para o enfrentamento da violência contra a mulher, (re)vitimizando este público, (re)colocando-o na condição de minoria. Um exemplo disso são os poucos temas não vinculados à reprodução ou vivência da sexualidade que "contaminam" a PNAISM: a potencialidade de ocupar o espaço de vítima de violência, ou questões étnico-raciais (a mulher negra), excluindo outras possibilidades de feminilidade. Outro aspecto relevante é a menção à população GLBTT (Gays, lésbicas, bissexuais, travestis e transexuais) no mesmo grupo de cuidados que o olhar para as mulheres necessita, estereotipando as necessidades de grupos diferentes e, tornando esses grupos homogêneos, passíveis de fragilidade e atestados como minorias.

Com o atravessamento das leis e políticas de saúde na prática profissional, a Psicologia implica-se em pensar e ressignificar as diretrizes estabelecidas para o trabalho em saúde com a população. Neste sentido, a eleição da integralidade parece ser uma escolha necessária para o entendimento da produção atual da Psicologia em relação à Saúde, posto ser tal diretriz, uma das três norteadoras do Sistema Único de Saúde do Brasil (com a equidade e a universalidade). Tal escolha complementa-se ao campo dos estudos de gênero (e, em especial no que diz respeito ao estudo das feminilidades), posto ser a PNAISM uma das mais estruturadas e enfatizadas políticas de saúde pública do SUS e, portanto, uma das que mais potencial de implicação para as práticas psicológicas produz.

\section{Método}

Após a discussão e esclarecimento de alguns conceitos básicos sobre saúde (em especial: saúde da mulher, políticas de saúde da mulher e integralidade), buscou-se analisar o que está sendo produzido em integralidade - especialmente integralidade da atenção à saúde da mulher - e de que forma esse conceito ressignifica a produção de conhecimento na interface saúde e psicologia. Além disso, buscou-se identificar quem está produzindo o conhecimento sobre integralidade no Brasil, sobre que temáticas associadas, onde e em que formatos.

0 processo de busca de publicações brasileiras foi realizado entre os meses de março e maio de 2010 nas bases de dados eletrônicas SciELO e PEPSIC. Para a realização da pesquisa, utilizou-se o descritor integralidade como palavra-chave para a busca. Após o levantamento realizado, o primeiro passo foi a consulta aos resumos e, posteriormente, a busca dos artigos originais.

Com a análise dos artigos, buscou-se identificar nas produções, quais as categorias dos artigos publicados, em quais revistas, qual o ano de publicação e a população pesquisada. 0 estudo divide-se em duas dimensões: a quantitativa, onde se apresentam as análises descritivas, de toda a produção nacional sobre integralidade nas duas bases de dados nacionais já citadas. A dimensão qualitativa analisa especificamente aquelas produções que tentavam vincular o conceito de integralidade à saúde da mulher e que partiam do referencial ou da autoria explicitamente vinculados à Psicologia.

\section{Resultados}

Dimensão quantitativa: Caracterização geral da produção científica sobre integralidade em saúde

Os resultados foram organizados de maneira a ilustrar, inicialmente, os dados gerais sobre a produção acadêmica nacional sobre a integralidade, para apenas posteriormente analisar com maior profundidade os aspectos referentes à integralidade na saúde da mulher. A primeira tabela ilustra a categoria dos estudos. Há uma diferença expressiva entre os tipos de artigos encontrados nos bancos de dados. No SciELO, a produção é mais diversificada e são encontrados quatro tipos de categorias, como 
ilustra a Tabela 1. As categorias revisão teórica e relatos de pesquisas possuem números aproximados de produções, respectivamente 87 e 76 artigos. Porém, no PEPSIC, $75 \%$ da produção enquadram-se na categoria relatos de pesquisas e $25 \%$ relatos de experiências, não havendo publicações nas categorias revisão teórica ou estudos de caso, que figuram na base SciELO. Tal resultado leva a pensar em como a Psicologia prioritariamente produz seu conhecimento, de maneira marcadamente empiricista, enquanto a produção do conhecimento em integralidade/saúde que figura em uma base de dados multidisciplinar (como o SciELO) possui maior diversidade de formatos, o que talvez ilustre o amadurecimento das discussões e a maior apropriação do conceito por parte de outros profissionais da saúde.

Tabela 1 - Categorias das publicaçōes sobre integralidade

\begin{tabular}{lcccc}
\hline \multirow{2}{*}{\multicolumn{1}{c}{ Categoria }} & \multicolumn{2}{c}{ SciELO } & \multicolumn{2}{c}{ PEPSIC } \\
\cline { 2 - 5 } & $\mathbf{n}$ & $\mathbf{\%}$ & $\mathbf{n}$ & $\%$ \\
\hline Relato de pesquisa & 76 & 41,08 & 6 & 75 \\
Revisão teórica & 87 & 47,03 & 0 & 0 \\
Estudo de caso & 10 & 5,41 & 0 & 0 \\
Relato de experiência & 12 & 6,49 & 2 & 25 \\
\hline
\end{tabular}

Fonte: Dados da pesquisa.

Já na Tabela 2, apresenta-se a distribuição das produções segundo os tipos de revistas. Divididas em dois grupos, um em que figuram as produções encontradas nas revistas específicas da área da Psicologia e outro de revistas de áreas afins (saúde). Analisando a Tabela 2, pode-se observar no que diz respeito especificamente às revistas da área da Psicologia, há mais publicações sobre integralidade na base PEPSIC, do que no SciELO. Das seis revistas da área da Psicologia, nas quais se encontram artigos com o descritor "integralidade", cinco estão publicadas no banco de dados PEPSIC. Ainda, no PEPSIC, a revista onde mais foram encontradas publicações foi a Aletheia, com duas.

Já no SciELO, é possível encontrar um número mais significativo quanto a diferentes tipos de revistas e publicações com o mesmo descritor. Com um total de 185 publicações divididas em 27 revistas diferentes. Podemos encontrar um maior número de publicações na revista Ciência e Saúde Coletiva, com $20 \%$ dos artigos encontrados.

Para uma melhor compreensão desses resultados, buscou-se a missão das revistas. No site Scielo, é possível encontrar esse dado, portanto buscamos a missão das revistas que apresentaram o maior número de publicações. Especificamente na área da Psicologia, nessa base de dados, as publicações se concentram na revista Psicologia e Sociedade (Revista da Associação Brasileira de Psicologia Social), no qual foi possível encontrar quatro artigos publicados. Sua missão tem uma postura interdisciplinar, considerando o desenvolvimento da Psicologia Social.

Publicar artigos originais sobre temáticas que privilegiem pesquisas e discussões na interface entre a psicologia e a sociedade, tendo em vista o desenvolvimento da Psicologia Social numa postura crítica, transformadora e interdisciplinar (ABRAPSO, 2010).

Nas publicações de áreas afins (entenda-se, basicamente, área da saúde) buscaram-se as três revistas com mais publicações. A revista com maior número de publicações é a Ciência e Saúde Coletiva, com 37 artigos. Nela é possível encontrar, como missão, questões pertinentes à Saúde coletiva: "Publicar debates, análises e resultados de investigações sobre temas considerados relevantes para a Saúde Coletiva (ABPGSC, 2010). A segunda revista em quantidade de publicações é a Cadernos de Saúde Pública que, conforme o nome, tem como missão a publicação de assuntos relacionados à Saúde Pública, porém bastante mais abrangente quanto ao escopo:

Publicar artigos originais que contribuam para o estudo da saúde pública em geral e disciplinas afins, como Epidemiologia, Nutrição, Parasitologia, Ecologia e Controles de Vetores, Saúde Ambiental, Políticas Públicas e Planejamento em Saúde, Ciências Sociais Aplicadas à Saúde, dentre outras (Fiocruz, 2010).

Já a terceira revista que buscamos a missão, com 20 artigos publicados, é a Saúde e Sociedade, que aceita publicações em diversos campos da saúde. Divulgar a produção das diferentes áreas do saber, sobre práticas da saúde, visando ao desenvolvimento interdisciplinar do campo da saúde pública (FSP / USP, 2010). 
Tabela 2 - Revistas: distribuiç̃óo das produçōes, segundo o nome e tipo de revistas

\begin{tabular}{|c|c|c|c|c|}
\hline \multirow{2}{*}{ Revistas } & \multicolumn{2}{|c|}{ SciELO } & \multicolumn{2}{|c|}{ PEPSIC } \\
\hline & $\mathbf{n}$ & $\%$ & n & $\%$ \\
\hline \multicolumn{5}{|c|}{ Psicologia } \\
\hline Aletheia & 0 & 0 & 2 & 25 \\
\hline Bol. Psico & 0 & 0 & 1 & 12,5 \\
\hline Psicologia Ciência e Profissão & 0 & 0 & 1 & 12,5 \\
\hline Psicologia USP & 0 & 0 & 1 & 12,5 \\
\hline Psicologia e Sociedade & 4 & 2,16 & 0 & 0 \\
\hline Psico USF & 0 & 0 & 1 & 12,5 \\
\hline \multicolumn{5}{|c|}{ Áreas Afins } \\
\hline Acta Paulista de Enfermagem & 3 & 1,62 & 0 & 0 \\
\hline Avaliação Campinas & 1 & 0,54 & 0 & 0 \\
\hline Cadernos de Saúde Pública & 30 & 16,22 & 0 & 0 \\
\hline Ciência e Saúde Coletiva & 37 & 20,0 & 0 & 0 \\
\hline Ensaio: Avaliação e Políticas Públicas em Educação & 1 & 0,54 & 0 & 0 \\
\hline Estudos Avançados & 2 & 1,08 & 0 & 0 \\
\hline História, Ciências, Saúde & 2 & 1,08 & 0 & 0 \\
\hline Horizontes Antropológicos & 1 & 0,54 & 0 & 0 \\
\hline Interface: Comunicação, Saúde e Educação & 18 & 9,73 & 0 & 0 \\
\hline Jornal de Pediatria & 1 & 0,54 & 0 & 0 \\
\hline Physis: Revista de Saúde Coletiva & 8 & 4,32 & 0 & 0 \\
\hline Revista Brasileira de Cresc. e Desen. Humano & 0 & 0 & 1 & 12,5 \\
\hline Revista Brasileira de Educação Médica & 3 & 1,62 & 0 & 0 \\
\hline Revista Brasileira de Enfermagem & 10 & 5,41 & 0 & 0 \\
\hline Revista Brasileira de Epidemiologia & 2 & 1,08 & 0 & 0 \\
\hline Revista Brasileira de Reumatologia & 1 & 0,54 & 0 & 0 \\
\hline Revista Brasileira de Saúde Materno Infantil & 2 & 1,08 & 0 & 0 \\
\hline Revista CEFAC & 2 & 1,08 & 0 & 0 \\
\hline Revista da Associação Médica Brasileira & 1 & 0,54 & 0 & 0 \\
\hline Revista da Escola de Enfermagem USP & 12 & 6,49 & 0 & 0 \\
\hline Revista da Sociedade Brasileira de Fonoaudiologia & 1 & 0,54 & 0 & 0 \\
\hline Revista de Administração Pública & 1 & 0,54 & 0 & 0 \\
\hline Revista de Saúde Pública & 9 & 4,86 & 0 & 0 \\
\hline Revista Estudos Feministas & 1 & 0,54 & 0 & 0 \\
\hline Revista Latino americana de Enfermagem & 1 & 0,54 & 0 & 0 \\
\hline Saúde e Sociedade & 20 & 10,81 & 0 & 0 \\
\hline Revista Eletrônica de Saúde Mental, Álcool e Drogas & 0 & 0 & 1 & 12,5 \\
\hline Texto e Contexto - Enfermagem & 11 & 5,95 & 0 & 0 \\
\hline
\end{tabular}

Fonte: Dados da pesquisa. 
Na Tabela 3, apresentam-se os dados referentes à formação dos autores indicada nos artigos, onde podem encontrar-se muitas áreas de profissionais que produzem sobre a integralidade. Além da especificidade da formação, considerou-se também quatro opções diferentes: Autoria Multidisciplinar com Psicólogo (onde há mais de um profissional envolvido na produção e estes são de áreas diferentes, com a participação de pelo menos um psicólogo); Autoria Multidisciplinar sem Psicólogo; Autoria de Gestores em Saúde (artigos que o(s) autor(es) não explicitou(aram) sua formação, mas seu cargo. Por exemplo, Secretaria da Saúde de determinado município, Secretários de Saúde) e Professores (autores que apresentam-se por meio de Secretarias de Educação, Departamentos de Educação ou mesmo de cursos superiores específicos).

No PEPSIC, foi encontrado o maior número de publicações explicitamente escritas por psicólogos $(62,5 \%)$, além de $25 \%$ de publicações de autoria multidisciplinar com psicólogo. Se somarmos o número de artigos que incluem o psicólogo, não necessariamente sendo exclusivo, chega-se a um percentual de $87,5 \%$, abrangendo, assim, a maioria das publicações. Porém, no SciELO, não é possível encontrar um número semelhante, já que o maior índice de autorias é multidisciplinar, sem psicólogo, $(29,73 \%)$, e a percentagem de artigos encontrados escritos exclusivamente por psicólogos é 4,86\%. Se houvesse a organização de um ranking, o psicólogo ocuparia o sétimo lugar dentre as 11 posições de formação dos autores sobre integralidade, o que reflete a quão incipiente tal temática se configura na produção acadêmica em Psicologia. Os resultados do PEPSIC apresentam-se como uma referência muito relativa, pois, ao tratar-se de uma base de dados específica da Psicologia, é natural que a formação da maioria dos autores se organize assim.

A produção sobre integralidade caracteriza-se predominantemente como uma produção de área multidisciplinar. Sobre os números encontrados de artigos em autoria multidisciplinar, encontra-se um percentual de mais de 35\%. Além disso, chama a atenção o percentual de mais de $25 \%$ das autorias identificadas com a área da Educação. Aparentemente, boa parte dessa produção remete à formação de profissionais em saúde e à importância de inserir a integralidade no eixo formativo dos profissionais e das práticas da área da saúde. Talvez os profissionais da área da Educação consigam ocupar um espaço que a Psicologia (ainda) não consegue. A temática da integralidade é muito associada a uma epistemologia típica das Ciências Humanas e, nesse sentido, a própria natureza da Psicologia poderia contribuir na discussão, caso não houvesse um viés absolutamente clínico, individualizante e "especializante" na formação desses profissionais (Spink, 2003). Tal configuração remete a crítica à segmentarização da construção do conhecimento - ainda vigente na academia - e que é absolutamente incompatível com o construto estudado, posto que a integralidade, por definição, já é entendida com um caráter transdisciplinar. A mesma autora define que a integralidade é

Tabela 3 - Formaç̃̃o profissional dos autores das produções sobre integralidade

\begin{tabular}{|c|c|c|c|c|}
\hline \multirow{2}{*}{ Formação dos/das autores(as) } & \multicolumn{2}{|c|}{ SciELO } & \multicolumn{2}{|c|}{ PEPSIC } \\
\hline & $\mathbf{n}$ & $\%$ & $\mathbf{n}$ & $\%$ \\
\hline Educação & 47 & 25,41 & 0 & 0 \\
\hline Enfermagem & 25 & 13,51 & 1 & 12,5 \\
\hline Fonoaudiologia & 2 & 1,07 & 0 & 0 \\
\hline Geografia & 1 & 0,54 & 0 & 0 \\
\hline Gestão em Saúde & 14 & 7,57 & 0 & 0 \\
\hline Medicina & 16 & 8,65 & 0 & 0 \\
\hline Multidisciplinar com Psicólogo & 11 & 5,95 & 2 & 25 \\
\hline Multidisciplinar sem Psicólogo & 55 & 29,73 & 0 & 0 \\
\hline Odontologia & 4 & 2,16 & 0 & 0 \\
\hline Psicologia & 7 & 4,86 & 5 & 62,5 \\
\hline Sociologia & 1 & 0,54 & 0 & 0 \\
\hline
\end{tabular}

Fonte: Dados da pesquisa. 
da ordem da multidisciplinaridade e envolve múltiplas especialidades que se entrecruzam para dar resposta a demandas e necessidades (Spink, 2007). Na construção de um processo interdisciplinar de compreensão da integralidade, a utopia da

... transdisciplinariedade possibilita pensar problemas não resolvidos por uma área, por meio do diálogo entre áreas e pesquisadores, podendo funcionar como dispositivo que faz avançar relações. Sua origem está no trabalho em equipe cujo compromisso é a geração de dispositivos renovados para o trabalho, sendo necessário que cada profissional se familiarize com as outras áreas, de modo legitimado e em relações horizontais. Requer humildade e disponibilidade, num movimento de reconhecimento de dificuldades insolúveis e de posições diferentes em relação a um mesmo objeto (Garcia et al., 2006, p. 475).

Na Tabela 4, descrevem-se os anos das publicações. Pode-se observar o crescimento de publicações sobre integralidade nos últimos anos. No SciELO, é possível encontrar 19 artigos em 2004 e em 2009 esse número salta a 49 estudos. Analisando os dados, pode-se dizer que o crescimento é superior a $16 \%$.

Tabela 4 - Ano de publicação dos artigos pesquisados

\begin{tabular}{ccccc}
\hline \multirow{2}{*}{$\begin{array}{c}\text { Ano de } \\
\text { publicação }\end{array}$} & \multicolumn{2}{c}{ SciELO } & \multicolumn{2}{c}{ PEPSIC } \\
\cline { 2 - 5 } & $\mathbf{n}$ & \% & $\mathbf{n}$ & $\%$ \\
\hline 2010 & 5 & 2,7 & 0 & 0 \\
2009 & 49 & 26,49 & 2 & 25 \\
2008 & 36 & 19,46 & 0 & 0 \\
2007 & 30 & 16,22 & 5 & 62,5 \\
\hline 2006 & 17 & 9,19 & 1 & 12,5 \\
2005 & 10 & 5,41 & 0 & 0 \\
\hline 2004 & 19 & 10,27 & 0 & 0 \\
\hline 2003 & 3 & 1,62 & 0 & 0 \\
\hline 2002 & 8 & 4,32 & 0 & 0 \\
\hline 2001 & 2 & 1,08 & 0 & 0 \\
\hline 2000 & 1 & 0,54 & 0 & 0 \\
\hline 1999 & 3 & 1,62 & 0 & 0 \\
\hline 1998 & 2 & 1,08 & 0 & 0 \\
\hline
\end{tabular}

Fonte: Dados da pesquisa.

Porém, ao se observarem os resultados encontrados no PEPSIC, esses dados não nos remetem às mesmas constatações, já que não houve um crescimento com o passar dos anos e caracterizando a tímida apropriação que a teorização em Psicologia faz sobre esse conceito.

A Tabela 5, denominada formato/participantes do estudo, traz dados referentes à população estudada ou à forma do artigo, quando não se tratava de artigo empírico (pesquisa ou experiência). Separou-se por categorias, e, no SciELO o maior percentual encontrado foi de $47,03 \%$ e este se refere ao que nomeamos de conhecimento, avaliação de projetos e/ou programas. No PEPSIC, o índice não nos traz os mesmos dados, já que neste o maior percentual se deu como público-alvo os profissionais, com $50 \%$ dos artigos encontrados.

Para que fiquem mais claros os demais indicadores, foram categorizados os diferentes tipos de população estudada. A primeira é profissionais $e$ usuários, e se refere às pesquisas em que ambos são referidos no estudo. A segunda é a de profissionais: prestação de serviços, que engloba os estudos que tratam da avaliação da qualidade de prestação de serviços que os profissionais prestam à comunidade. Já a categoria profissionais, trata de estudos com os profissionais, qualidade de vida no trabalho, condições de trabalho e formação destes. A última é a usuários, que trata de estudos que tem como público alvo usuários e usuárias do sistema de saúde.

\section{Tabela 5 - Participantes/Formato do estudo: distribuição quanto ao público-alvo dos estudos}

\begin{tabular}{lcccc}
\hline \multirow{2}{*}{$\begin{array}{l}\text { Participantes/Formato } \\
\text { do estudo }\end{array}$} & \multicolumn{2}{c}{ SciELO } & \multicolumn{2}{c}{ PEPSIC } \\
\cline { 2 - 5 } & $\mathbf{n}$ & $\mathbf{\%}$ & $\mathbf{n}$ & $\%$ \\
\hline $\begin{array}{l}\text { Conhecimento, avaliação } \\
\text { de projetos e programas }\end{array}$ & 87 & 47,03 & 2 & 25 \\
Profissionais & 43 & 23,24 & 4 & 50 \\
Profissionais e usuários & 3 & 1,62 & 0 & 0 \\
$\begin{array}{l}\text { Profissionais: prestação } \\
\text { de serviços }\end{array}$ & 27 & 14,59 & 0 & 0 \\
Usuários & 25 & 13,51 & 2 & 25 \\
\hline
\end{tabular}

Fonte: Dados da pesquisa.

\section{Dimensão qualitativa: Aproximações entre Psicologia e Integralidade à Saúde da Mulher}

Ao analisar qualitativamente a produção de interface explícita entre a Psicologia e a Integralidade, verificou-se que há uma preocupação quanto à efetividade dessa premissa, especialmente na implantação 
de ações em saúde associadas ao SUS, mesmo que os artigos tenham sido apenas quatro. Considerando que o objetivo deste estudo é identificar, nas produções, principalmente de psicólogos, a integralidade à saúde da mulher encontraram-se poucos artigos. Porém, dentro das contribuições da Psicologia para a construção da integralidade, a questão do gênero e saúde para a mulher é bastante discutida nos artigos encontrados. Como é no caso de: Políticas públicas de saúde da mulher: A integralidade em questão:

Objetivamos problematizar o que tomamos como integralidade na efetividade dos cuidados em relação à saúde da mulher. Para isso, utilizamos um recorte no texto introdutório realizado pela Secretaria da Saúde do Rio Grande do Sul, em sua página na Internet, como um exercício para circunscrever essa questão. Esse recorte do texto é dividido em três partes, sendo cada uma delas discutida por um eixo de formulações para problematizar a integralidade: a mulher como sujeito da saúde; o Programa de Assistência Integral à Saúde da Mulher (PAISM) como a conformação de um determinado campo de saúde para mulheres; e a produção de conhecimento científico para o fazer no campo da saúde pública (Medeiros \& Guareschi, 2009, p. 31).

A importância da criação de programas, levando em conta a identidade de gênero é fundamental, já que podemos orientar práticas que contemplem a integralidade, mas Lionço (2008) nos alerta de que a orientação sexual e a identidade de gênero, mais do que demandar uma política específica, devem ser pauta para diversas (micro)políticas enquanto determinantes associados a outros fatores significatos da e na saúde das pessoas. Nesse sentido, é importante a leitura de Gomes (2009) e Arilha, Ubenhaum e Medrado (1998) sobre as diversas facetas da identidade de gênero, já que podemos pensar em diversas masculinidades e, assim, também diversas feminilidades.

No artigo: "Que direito à saúde para a população GLBT? Considerando direitos humanos, sexuais e reprodutivos em busca da integralidade e da equidade", propõe-se uma mudança na compreensão do conceito de integralidade em relação ao gênero.

A partir da consideração dos processos de violação de seus direitos humanos, sistematicamente comprometidos devido a estigmas e processos discriminatórios, busca-se evidenciar a necessidade de uma política de saúde específica a esta população, na perspectiva da integralidade da atenção e da equidade no sistema de saúde. 0 desafio da construção de uma política de atenção integral à saúde dessa população, tal como prevista no programa de governo federal Brasil sem Homofobia, implica a complexificação e alargamento do que se compreende por direitos sexuais e reprodutivos para a efetiva promoção da equidade e universalidade do acesso aos bens e serviços (Lionço, 2008, p. 11).

Nesses dois artigos, assim como nos demais encontrados em nossa pesquisa, há um questionamento no que se refere à efetividade da integralidade, mais especificamente nos dois últimos tratados aqui. Um sugere a criação de uma política explícita para a atenção à saúde GLBT (Gays, lésbicas, bissexuais e transexuais) e o outro questiona que integralidade há nesta política criada para a saúde da mulher, já que continua tratando de mamas, colo e gestação como focos prioritários. A crítica que esses autores trazem é que, mesmo que a política criada tenha, em seu discurso, a ampliação do olhar técnico em saúde, o que parece é que, neste caso, a atenção às mulheres ainda é pautada sobre os caracteres sexuais ligados à maternidade, mantendo estereótipos. Já a saúde da população GLBT parece acoplar-se às vitimizações, estereotipias e exclusões a que são submetidas as mulheres, uma vez que as políticas específicas para tais populações está diretamente vinculada à PNAISM.

Medeiros e Guareschi (2009) trazem como o corpo da mulher ainda é visto como corpo reprodutivo. Isso se torna evidente quando voltamos o olhar ao PNAISM, que tem como um dos itens o planejamento familiar. Vincula-se à mulher como núcleo estruturante da família, que deve ser auxiliada pelos filhos e maridos para manter essa estrutura. Esse fortalecimento dos estereótipos reforça como o conceito de feminilidade não está desvinculado da maternidade, o que, por um lado, não deixa de ser evidente, dada a condição biológica da mulher. Porém torna o homem também engessado num papel de gênero até mesmo dentro da família, que deve ser formada por mulher e homem, desconsiderando outras possibilidades que podem surgir como uniões homossexuais ou maternidade/paternidade individual. Garcia (1998) nos incita o questionamento das relações de poder instituídas pelas identidades de gênero, já que pensamos, mesmo sem atinar, que as noções de masculino e feminino são construídas tanto dialógica, em complementação, quanto dialeticamente, uma contrapondo a outra, o que nos leva muitas vezes à manutenção de estereótipos e relações assimétricas de poder e, ao nosso ver, a criação de políticas e programas também 
passa pela manutenção desse tipo construído de relações de gênero e poder.

Nesta linha, é importante elevar alguns pontos do artigo "Processos de (re)construção de um grupo de planejamento familiar: uma proposta de educação popular em saúde". Nesse artigo, a forma como o planejamento familiar é abordado subverte a lógica da PNAISM e tira o sujeito de um local apenas biológico, marcado pela reprodução da espécie controlada e, assim, "planejada" pelas ações baseadas na política: distribuição e acesso a métodos contraceptivos. Coloca em questão uma forma de planejamento diário, vendo a família como um interlocutor cultural:

... nestes encontros são abordados ... assuntos referentes à: DSTs, prevenção de colo do útero, informações sobre métodos contraceptivos, sexualidade ... limites na educação dos filhos, amor próprio (Pereira et al., 2007, p. 323-324).

Por esse trecho, vemos como o conceito de integralidade pode ser utilizado, quando sobrepujamos as barreiras do biológico e olhamos para um ser humano com necessidades no processo saúde-doença que perpassam o âmbito sócio-histórico. Essa noção ampliada de ser humano é trabalhada no artigo "Histórias de vida de mulheres e saúde da família: algumas reflexões sobre gênero"

... no trabalho em Saúde da Família, a mulher não pode ser vista a priori como mãe, antes como mulher e, sobretudo, como Sujeito. E, sendo o psíquico tão importante quanto o físico, a integralidade deve ser movida pela ética da solidariedade e do reconhecimento do outro como merecedor de compaixão, seja ele quem for (Barbarini \& Benites, 2009, p. 22).

Vemos, nesse trecho, a importância que deve ser dada ao conceito de integralidade não como simples orientação, mas como visão de ser humano, algo que muitas vezes fica apenas no discurso dos profissionais, já que a implementação dessa diretriz nos fazeres psicológicos em saúde é recente e sua ativação necessita de uma ampliação dos paradigmas tradicionais (biomédicos) no cuidado à saúde.

\section{Considerações finais}

Nos estudos encontrados e analisados na área da Psicologia, o que se encontra, prioritariamente, é a referência à Psicologia Social como subárea constituinte desse campo de problematizações, especialmente no que diz respeito às produções de psicólogos diretamente implicados na construção de novas práticas e saberes no SUS. A Integralidade à Saúde da Mulher na Psicologia está intimamente ligada a esses dois marcadores: o SUS enquanto cenários de práticas; e a Psicologia Social enquanto marco referencial.

No entanto, ao que parece, ainda vigora uma noção de sujeito fragmentado, individualizado e contaminado pela hegemonia do modelo médico/ biomédico na maior parte das produções sobre integralidade e saúde da mulher, em muitas tentativas de validação das experiências de prática em saúde advindas da PNAISM. Isso é revelado também nas políticas que norteiam ações, havendo poucas publicações - especialmente as fortemente vinculadas à Psicologia Social - que rompem com tais vieses. Essa busca implica repensarmos as diretrizes e práticas tanto da formação profissional e seus discursos acadêmicos, quanto nas políticas que nos são impostas como base para atuação, como norma estatal, já que o SUS é uma garantia de Estado. Estamos em uma vivência de busca do saber, de conhecer o espaço em que as pessoas atuam e, para compreender os diferentes significados que a integralidade à saúde da mulher pode ocupar nos espaços de produção de conhecimento da Psicologia e das demais áreas da Saúde.

Com base na dimensão quantitativa do estudo, pode-se observar que ainda é muito pequeno o número de publicações em que todos os autores são psicólogos ou psicólogas. Também esse número é reduzido quando está atuando com outros profissionais ou até mesmo com uma equipe multiprofissional. Há muitos estudos que trabalham com resultados ou apresentação de programas, projetos, relacionado à saúde da mulher, nas quais o SUS e seus atores são analisados, ora com questões relacionadas à sua efetividade, ora com a qualidade do serviço prestado ou profissionais (seja ele pelo lado positivo ou negativo). Tal panorama evidencia um distanciamento ainda existente da psicologia em relação às práticas e às produções de saberes em saúde coletiva.

Espera-se que chegue o momento em que a saúde seja o foco de olhar dos profissionais da psicologia em todo âmbito do cuidado e que questões culturais e contextuais sejam incorporadas às equipes de cuidado nas quais os profissionais da área ainda necessitam conquistar um espaço efetivo e implicado. 


\section{Referências}

Arilha, M., Ubenhaum, S. G., \& Medrado, B. (Org.). (1998). Homens \& Masculinidades: Outras palavras. São Paulo: Editora 34.

Associação Brasileira de Psicologia Social - ABRAPSO. (2010). Instruções aos Autores. Psicologia e Sociedade. Recuperado em 20 jul. 2010, em http:// www.scielo.br/revistas/psoc/iinstruc.htm

Barbarini, N., \& Benites, A. P. O. (2009). Histórias de vida de mulheres e saúde da família: Algumas reflexões sobre gênero. Psicologia e Sociedade, 21(1), 16-24.

Brasil. (1990a). Lei n. 8.080, de 19 de setembro de 1990. Dispõe sobre as condições para a promoção, proteção e recuperação da saúde, a organização e o funcionamento dos serviços correspondentes e dá outras providências. Diário Oficial [da] República Federativa do Brasil, Poder Legislativo, Brasília, DF, 19 set. 1990. Recuperado em 20 jul. 2010, em http:// www.planalto.gov.br/ccivil_03/leis/l8080.htm

Brasil. (1990b). Lei n. 8.142, de 28 de dezembro de 1990. Dispõe sobre a participação da comunidade na gestão do Sistema Único de Saúde (SUS) e sobre as transferências intergovernamentais de recursos financeiros na área da saúde e dá outras providências. Diário Oficial [da] República Federativa do Brasil, Poder Legislativo, Brasília, DF, 28 dez. 1990. Recuperado em 20 jul. 2010, em http://www.planalto.gov.br/ccivil_03/leis/L8142.htm

Brasil. (2000). Legislação Federal e Estadual do SUS SUS é Legal. Brasília: Governo do Rio Grande do Sul; Secretaria da Saúde; Conselho Estadual de Saúde.

Brasil. (2004). Política Nacional de Atenção Integral à Saúde da Mulher: Princípios e Diretrizes. Brasília: Secretaria de Atenção a Saúde, Departamento de Ações Programáticas Estratégicas; Ministério da Saúde. (Serie C. Projetos, Programas e Relatórios).

Farah, M. (2004). Gênero e políticas públicas. Revista Estudos Feministas, 12(1), 47-71.

Fundação Oswaldo Cruz, [Fiocruz], (2010). Instruções aos autores. Cadernos de Saúde Pública. Recuperado em 20 jul. 2010, em http://www4.ensp.fiocruz.br/csp/

Garcia, M. A. A., Pinto, A., Odonia. P. C., Longhi B. S., Machado L. I., Linek M. D. S. et al. (2006). Interdisciplinariedade e integralidade do ensino em saúde. Revista de Ciências Médicas, 15(6), 473-485.
Garcia, S. M. (1998). Conhecer os homens a partir do gênero e para além do gênero. In M. Arilha, S. G. Ubenhaum \& B. Medrado (Org.). (1998). Homens \& masculinidades: Outras palavras. São Paulo: Editora 34.

Giffin, K. M. (1991). Mulher e saúde. Cadernos de Saúde Pública, 7(2), 133-134.

Gomes, R. (2009). Sexualidade masculina, saúde e gênero. Rio de Janeiro: Fiocruz.

Instituto de Defesa do Consumidor - IDEC. (2006). O SUS pode ser o seu melhor plano de saúde (3. ed.). Brasília: IDEC.

Lionço, T. (2008). Que direito à saúde para a população GLBT? Considerando direitos humanos, sexuais e reprodutivos em busca da integralidade e da equidade. Saúde e Sociedade, 17(2), 11-21.

Mattos, R. A. (2001). Os sentidos da integralidade: Algumas reflexões acerca de valores que merecem ser defendidos. In R. Pinheiro \& R. A. Mattos (Ed.). Os sentidos da integralidade na atenção e no cuidado à saúde (pp. 39-64). Rio de Janeiro: Abrasco.

Medeiros, P. F., Bernardes, A., \& Guareschi, N. M. de F. (2005). 0 conceito de saúde e suas implicações nas práticas psicológicas. Psicologia: Teoria e Pesquisa, 21(3), 263-269.

Medeiros, P. F. de, \& Guareschi, N. M. de F. (2009). Políticas públicas de saúde da mulher: a integralidade em questão. Estudos Feministas, 17(1), 31-34.

Ministério da Saúde. (2010a). Apresentação: Sistema Único de Saúde. Recuperado em 12 out. 2010, em http://portal.saude.gov.br/portal/saude/cidadao/ visualizar_texto.cfm?idtxt=29178\&janela $=1$

Ministério da Saúde. (2010b). Saúde da mulher. Recuperado em 12 out. 2010, em http://portal.saude.gov. $\mathrm{br} /$ portal/saude/area.cfm?id_area $=152$

Pereira Q. L. C., Silva, C.B.D.C.A., Pelzer, M.T., Lunardi, V. L., \& Siqueira, H.C.H. (2007). Processo de (re)construção de um grupo de planejamento familiar: Uma proposta de educação popular em saúde. Texto contexto Enfermagem, 16(2), 320-325.

Spink, M. J. P. (2003). Psicologia social e saúde: Práticas, saberes e sentidos (4. ed.). Petrópolis: Vozes.

Spink, M. J. P. (2007). Sobre a possibilidade de conciliação do ideal da integralidade nos cuidados à saúde e a cacofonia da demanda. Saúde e Sociedade, 16(1), 18-27. 